\title{
AVALIAÇÃO ESCOLAR - UMA PRÁTICA ENTRE DUAS LÓGICAS: A QUE EMANCIPA E A QUE REPRODUZ AS DESIGUALDADES SOCIAIS
}

\author{
Vera Regina Souza dos Santos \\ Universidade Federal do Estado do Rio de Janeiro (UNIRIO), Rio de \\ Janeiro, Rio de Janeiro, Brasil
}

\begin{abstract}
Resumo: Este trabalho busca, por meio de uma análise bibliográfica, propor reflexões acerca da avaliação escolar. Mostra que essa prática, na escola de Educação Básica, tem se constituído em uma das questões centrais do trabalho docente. Analisa as diferentes funções da avaliação e discute as representações de professores e professoras, identificando os equívocos que a rodeiam. Sinaliza a necessidade de rompimento com paradigmas educacionais que a concebem como mecanismo reprodutor das desigualdades e ressalta a necessidade de que se constitua uma ação que permita abarcar a multiplicidade de situações e processos de desenvolvimento dos/das estudantes como uma medida importante, no campo da educação, para romper as desigualdades sociais.
\end{abstract}

Palavras-Chave: Avaliação. Inclusão Social. Ruptura epistemológica. Educação Básica.

INTRODUÇÃO

O indivíduo, na sua relação com o meio que o cerca, elabora significados próprios para as situações que vivencia. Suas vivências e suas representações da realidade constituem a sua bagagem cultural, que é singular e que será sempre o ponto de partida para todas as suas experiências. Sendo assim, na escola, as situações de aprendizagem que se proporcionarão a um grupo de estudantes se constituirão em tantas representações e possibilidades quantos forem os componentes desse grupo. Essa multiplicidade de processos, no entanto, frequentemente é desconsiderada pela escola, especialmente no que se refere à avaliação. Não raro, institui-se um padrão, um modelo, e o que é apresentado pelos/pelas estudantes é comparado a ele, estabelecendo-se uma hierarquização desses/dessas conforme se aproximem ou se distanciem daquele. $E$ aqueles/aquelas estudantes que, de acordo com essa perspectiva, não "aprendem", não atendem ao padrão mínimo exigido, são reprovados/reprovadas.

A avaliação, assim, volta-se apenas para a atividade do/da estudante, focalizando-a exclusivamente e estando relacionada ao simples julgamento de resultados. Nessa perspectiva, ela tem um caráter sentensivo, terminal, interferindo em processos de desenvolvimento ou promovendo a exclusão de muitos/muitas estudantes do espaço escolar. Tem-se aí um paradoxo, pois, sendo um espaço privilegiado para 
desenvolvimento de potencialidades, da cidadania e para a inclusão social, a instituição escolar acaba promovendo a exclusão.

Segundo Garcia (2003), podemos perceber, já no século XVII, formas de institucionalizar a avaliação, compreendo-a como ação para verificar o andamento da situação, assumindo, já aí, duas funções básicas: uma que a vê como um lugar de aprendizagem; e outra que a compreende como forma de supervisioná-la, controlá-la. A primeira é concebida por Comenius e encerra a ideia de que o exame deveria servir para promover a aprendizagem: sinalizando o estágio de desenvolvimento do/da estudante, ela teria a função de ajudar a repensar a prática pedagógica, a estabelecer outros caminhos para que se garantisse a aprendizagem a todos/todas. A "não aprendizagem" do/da estudante, nessa perspectiva, sinalizaria a necessidade de se repensar o método. A segunda tinha em La Salle um de seus mais ferrenhos defensores e compreendia o exame como uma forma de verificação da aprendizagem, simplesmente. Nessa perspectiva, a avaliação sentenciava sem se preocupar com uma análise ou uma reflexão a partir dos resultados obtidos.

As proposições de La Salle, segundo Garcia (2003), exerceram forte influência sobre a organização dos sistemas escolares desde então. Sendo que o modelo de avaliação que predomina nas escolas, ainda hoje, é herdeiro das concepções desse autor. Essas proposições conformaram a avaliação à ideia de verificação dos resultados. Nessa perspectiva, algumas vezes a preocupação recaiu sobre o objeto de conhecimento; em outras, sobre o sujeito/indivíduo. Em ambos os casos, no entanto, ela se manteve excludente, pois sempre esteve presente uma ideia de um padrão a ser alcançado. Visto que a escola é uma instituição social - e, como tal, por ela transitam os valores da sociedade em que está inserida - verifica-se que um modelo de avaliação está intrinsecamente relacionado a um modelo de sociedade. Se a prática avaliativa é excludente, ela revela os valores de uma sociedade que certamente também é excludente.

Neste sentido, houve movimentos no campo da avaliação para mudar essa perspectiva de exclusão. Alguns estudos demonstraram a necessidade de compreendê-la como sinalizadora para o/a professor/professora; do rumo que o trabalho estava seguindo e de verificação do significado que os/as estudantes estavam dando para as situações de aprendizagem às quais eram submetidos/submetidas, em uma perspectiva de compreensão dos processos desenvolvidos e de respeito a eles. Nesse contexto, no Brasil, despontaram os estudos de Esteban (2002) e de Hoffmann (2005), lançando um novo olhar sobre o que, na escola, convencionou-se denominar erro. A primeira foi mais longe nesse debate e propôs, alinhando-se a Barriga (1982) e Santos (1993), uma ruptura com o paradigma epistemológico predominante.

Objetivando analisar as diferentes funções da avaliação e verificar de que forma contribuem para a dinâmica inclusão/exclusão escolar, este trabalho consiste numa análise bibliográfica do tema e apresenta uma proposta de superação da visão sentensiva e classificatória que é uma das causas da reprovação escolar. Sua relevância está na necessidade premente de reconfigurar as práticas avaliativas - que não têm contribuído com eficácia para o pleno desenvolvimento escolar dos/das estudantes. $O$ trabalho 
encontra-se dividido em duas partes. A primeira propõe-se a analisar os diferentes enfoques da avaliação da aprendizagem, relacionando-os a paradigmas educacionais e buscando compreender suas implicações na dinâmica escolar e nos processos de inclusão/exclusão sociais. Aqui, verificar-se-ão, também, quais são as representações mais comuns dos professores e das professoras sobre a avaliação.

A segunda parte aborda as funções da avaliação para, a seguir, analisar as representações docentes sobre essa prática. Busca estabelecer uma relação entre a ação avaliativa na escola e os processos mais gerais de inclusão/exclusão sociais, enfatizando a importância da ação educativa como medida que contribui para a diminuição das desigualdades sociais. Aqui se sinaliza o sentido que se busca para essa ação em uma perspectiva de inclusão social. Mostra que, para isso, têm contribuído muito os estudos no campo da cultura e, ligado a eles, a proposta radical de ruptura com o paradigma epistemológico que vem orientando as práticas escolares.

\section{PARADIGMAS EDUCACIONAIS E AVALIAÇão}

Sendo parte importante do processo pedagógico, a avaliação não está desvinculada de paradigmas educacionais. Podemos destacar, no âmbito educacional, dois grandes paradigmas orientando as práticas pedagógicas: o objetivista e 0 subjetivista. O primeiro pretende dar conta da realidade objetiva, acreditando, seus seguidores, ser possível a precisão e a fidedignidade de resultados, a imparcialidade do sujeito na relação com um dado objeto. Em termos de avaliação, o que as práticas impregnadas de tal paradigma procuram verificar é se o/a estudante domina conhecimentos que foram estabelecidos como imprescindíveis para ele/ela. Em qualquer nível de escolaridade, o que tal modelo de avaliação acaba fazendo é estabelecer um padrão ou parâmetro e comparar, a ele, o desenvolvimento dos/das estudantes. A pretensão de imparcialidade e de fidedignidade dos resultados deste paradigma nem sempre é uma meta alcançável. Em primeiro lugar, porque não considera dados relevantes do momento da avaliação, que podem interferir no resultado final, desconsiderando as influências que poderiam ter configurado aquele resultado. Em segundo lugar, porque não consegue captar - por não abrir espaço para tal - o que os/as estudantes sabem além daquilo que é cobrado, exigido como conhecimento válido.

Tendo em vista essa limitação do paradigma objetivista, cuja ênfase recaía sobre o objeto de conhecimento, foram formuladas concepções de avaliação que pretenderam dar conta da complexidade da ação pedagógica e que passaram a dar ênfase ao sujeito cognoscente. Assim, a partir das críticas àquele paradigma, surgiu o paradigma subjetivista que sinalizou um caminho possível em direção à construção da autonomia. Suas bases epistemológicas repousam na ideia de que a ciência não é neutra e de que tudo aquilo que o indivíduo produz está impregnado de suas vivências e experiências pessoais, como um ser situado em dado contexto sociocultural. Entretanto, conforme sinalizam alguns autores, esse paradigma, no campo educacional - devido às diversas tendências em seu interior - pode contribuir para a emancipação social ou manutenção do status quo. Bourdieu e Passeron (1975) chamam a atenção para o fato, 
sinalizando que ele pode estar a serviço da ideologia dominante, pode ser utilizado por determinados grupos para incutir certos valores.

Assim, mesmo se tratando de um paradigma que se preocupa com o processo de aprendizagem - e não com o produto final - nele pode-se entrever intencionalidade. Um exemplo é o modelo de avaliação para a tomada de decisão, conforme proposto por Stufflebean (1987), que - ao acreditar que os professores precisam diagnosticar os problemas que subjazem às aprendizagens de seus/suas estudantes e adequar seus procedimentos, estratégias e recursos para ajustá-los a um padrão ideal - pode servir também para moldar comportamentos. Ou seja, há aí uma preocupação com o processo de conhecimento do/da estudante; entretanto, há a intenção de ajustá-lo a um processo ideal, a um modelo que se acredita ser o adequado. A diferença é que esse paradigma pode promover mudanças sociais ao considerar as representações dos/das estudantes em outra perspectiva.

Franco (1995), tendo em vista essas e outras limitações do paradigma subjetivista, defende a existência de um terceiro paradigma: aquele que parte do vínculo indivíduo-sociedade em uma dimensão histórica. Segundo ela, aquele paradigma permanece no âmbito das análises abstratas e universais e perpetua conclusões centradas no indivíduo e em seus vínculos intimistas, desconsiderando a sua trajetória histórica. Assim, não contribui, segundo a autora, para favorecer o sucesso escolar das populações de baixa renda, portadoras de um repertório cultural diferente. Ainda de acordo com Franco, para compreender o indivíduo é preciso explicitar a especificidade de sua atividade no contexto de uma configuração social e partir de esquemas interpretativos baseados em teorias mais amplas que exponham a realidade em sua totalidade contraditória. Ela qualifica, assim, sob um novo paradigma, os modelos educacionais e avaliativos que procuram considerar as peculiaridades do contexto histórico-cultural em que se situa o/a estudante para promover a ruptura com os laços de dominação.

\section{FUNÇÕES SOMATIVA E FORMATIVA DA AVALIAÇÃO}

No âmbito dos debates sobre as limitações do paradigma objetivista, surgiu uma proposição que acabou se constituindo um marco importante para a reconceitualização no campo da educação. Proposta por Scriven, ela previa que o avaliador desconhecesse os objetivos do programa a ser avaliado e centrasse o trabalho de avaliação no sujeito, dirigindo seu olhar para as suas necessidades e procurando verificar a utilidade - para esse - do processo educacional. Ele reconheceu, na avaliação, duas funções principais: função formativa, que auxilia o aperfeiçoamento de determinado programa, devendo ser realizada pelos próprios participantes do processo com o objetivo de reconstruir o que não funciona adequadamente; e função somativa, que é desenvolvida por agentes externos ao programa e que compara os efeitos alcançados com as necessidades dos "consumidores", gerando uma valoração sobre o produto oferecido em relação aos demais.

No campo da avaliação da aprendizagem, mais especificamente, começou a haver, a partir dessas proposições, uma grande preocupação com os/as estudantes e com 
a adequação das propostas das atividades ao ritmo de cada um. A distinção apresentada por Scriven fez com que houvesse uma preocupação maior com o aspecto formativo da avaliação, centrando o processo avaliativo no atendimento às necessidades do/da estudante. Com o sujeito no centro do processo pedagógico, a perspectiva qualitativa da avaliação passou a valorizar as propostas que colaboravam com a construção da autonomia intelectual do/da estudante, buscando conhecer suas concepções, sentimentos e conhecimentos. Buscou compreender os processos cognitivos e fez emergir os traços subjetivos dos indivíduos. A preocupação, no ato avaliativo, passou a recair sobre a apreensão das habilidades que eles já possuíam ou estavam em processo de desenvolvimento.

Essa nova abordagem fez com que dados anteriormente negligenciados fossem tidos como necessários à avaliação, o que provocou uma demanda por novos instrumentos e procedimentos. Ela introduziu a preocupação com uma metodologia de avaliação que respeitasse as diferenças. Passou-se a almejar, ao avaliar, a libertação, a autonomia, a participação consciente do/da estudante em seu meio e a se elaborar objetivos para tal, empreendendo ajustes em auxílio aos estudantes em seu processo de desenvolvimento. Entretanto, é preciso ter em mente que o significado que aquele/aquela der ao que foi proposto no ato pedagógico pode ser diferente do que o/a professor/professora imaginou inicialmente, pois a experiência é sempre única para cada estudante, tendo em vista a realidade sociocultural na qual ele/ela se encontra ser única/singular. Tal fato, contudo, não nega a necessidade de mediação do/da professor/professora, auxiliando o/a estudante em seu processo de desenvolvimento.

Não obstante os diversos estudos e proposições, a avaliação ainda é fortemente marcada por uma concepção objetivista. Em nome de uma qualidade da educação, prevêse um único padrão de resposta que atenda ao que foi solicitado e desconsidera-se os outros conhecimentos que o/a estudante possui. Essa concepção de avaliação está em consonância com um modelo de educação neoliberal, em que não há espaço para as diferenças e que contribui para a universalização de modelos de comportamentos que Ihe são mais adequados. Isso tem implicações nos índices de reprovação escolar, pois tal perspectiva separa e promove aqueles/aquelas estudantes que se encaixam naquilo que a sociedade e a educação escolar valorizam e exclui e reprova quem não se encaixa. Temse, assim, uma forma de "controle social mediado pela prática pedagógica" (ESTEBAN, 2002, p. 102).

A avaliação colabora para a manutenção das desigualdades sociais, assim, por dois caminhos: primeiro, ao examinar apenas determinados conhecimentos, não havendo espaço para que outros conhecimentos adquiridos pelos/pelas estudantes possam ser verificados (e aqui cabem as perguntas: por que determinados conhecimentos são tidos como importantes? Quem os determinou como importantes? Eles atendem aos interesses de quem?). Em segundo lugar, ao valorizar determinados conhecimentos, só admite uma determinada lógica de compreensão, desconsiderando outras possíveis leituras feitas pelos/pelas estudantes.

\section{O/A PROFESSOR/PROFESSORA E SUAS REPRESENTAÇÕES SOBRE AVALIAÇÃO}


Essa perspectiva de avaliação ainda é comum nas escolas, constituindo uma prática indissociável da ação educativa que ainda é caracterizada exclusivamente por um julgamento de resultados. Para muitos professores, a avaliação é uma ação que tem um momento definido e seu objetivo é meramente o de verificar se o resultado apresentado pelos/pelas estudantes corresponde ao padrão definido como ideal. A partir daí, procedese a uma classificação deles/delas conforme se aproximem ou se distanciem de tal padrão. Segundo Hoffmann (2005), esse modelo tem sua origem nas concepções de Tyler, teórico norte-americano que preconizava a avaliação por objetivos. Segundo tal concepção, a avaliação constituiria em um processo destinado a verificar o grau em que mudanças comportamentais estão ocorrendo - mudanças estas previstas em objetivos definidos pelo/pela professor/professora.

Ainda segundo Hoffmann (2005), as críticas sofridas por essa concepção e os modelos contemporâneos não foram suficientes para derrubá-la. As exigências burocráticas dos sistemas de avaliação são um ponto que pode ajudar a explicá-la, segundo alguns autores. As experiências relacionadas à avaliação que tiveram os/as professores/professoras enquanto estudantes, assim como os referenciais teóricos que embasaram seus cursos de formação, também são outros pontos a considerar (NÓVOA, 1999). Percebe-se a influência dessa concepção na avaliação quando, segundo Hoffmann (2005), verifica-se, no início de um processo, o estabelecimento de objetivos e, em determinados intervalos, a verificação do alcance ou não dos mesmos. Verificações essas, ainda segundo ela, que são marcadas por imposições de terminologia: não raro a ação de avaliar é associada às ações de medir e de testar, não percebendo os/as docentes tratarse de ações conceitualmente diferentes.

Outros dois equívocos assinalados por ela são o fato de a medida assumir muitas vezes o papel absoluto nas decisões de aprovação/reprovação do/da estudante e o fato de o teste ser entendido como instrumento de mensuração/constatação e não de investigação. Segundo ela, o significado básico da palavra teste é verificação de funcionamento e implícita está uma ideia de ação ou de ajuste para que o trabalho siga seu curso normal. Estranhamente, na escola, a palavra adquiriu conotação contrária, representando - ao invés de instrumento de investigação - um instrumento de constatação, trazendo em seu bojo a concepção de estagnação, de procedimento terminal. As consequências desses equívocos, segundo a autora, são enormes. Em primeiro lugar, percebe-se a arbitrariedade que envolve a avaliação dos/das estudantes segundo esses princípios. A avaliação, assim, não aparece relacionada a pontos referenciais, não é negociada, tal como preconizam as concepções modernas e a pedagogia crítica: estudantes são avaliados/avaliadas sem saber que aspectos estão sendo priorizados.

Além disto, outras consequências desses equívocos são o fato de professores diferentes atribuírem notas ou conceitos diferentes a um mesmo aspecto, ou a um mesmo trabalho, em diferentes ocasiões. O reducionismo simplista da avaliação à concepção de medida representa, assim, uma barreira ao pleno desenvolvimento escolar dos/das estudantes. Nessa perspectiva, a essência da avaliação encontra-se comprometida. O seu significado como "interpretação cuidadosa e abrangente das respostas dos alunos frente 
a qualquer situação proposta" (HOFFMANN, 2005, p. 32) encontra-se distorcido. Para ela, o que se conseguiu apreender a partir das avaliações deveria servir de base para futuras ações do/da professor/professora no acompanhamento do desenvolvimento do/da estudante. Os resultados precisam ser o ponto de partida para o auxílio ao/à estudante na direção do seu processo de construção do conhecimento. Diante dos resultados apresentados, dever-se-ia procurar compreendê-lo melhor.

Uma prática pedagógica verdadeiramente preocupada em incluir, em promover o desenvolvimento do/da estudante deveria voltar-se para toda e qualquer atividade que ele/ela realiza com um olhar investigativo, tendo em vista auxiliá-lo/la em seu percurso. $O$ que, na escola, convencionou-se chamar de teste deveria ser encarado como mais uma tarefa realizada pelo/pela estudante, perdendo a tradicional significação de medição e constatação de resultados. Deveria também ser encarado como instrumento de investigação, não somente sobre a ação do/da estudante, mas também do/da professor/professora. As questões que deveriam nortear as investigações do/da docente, segundo Hoffmann (2005), são: qual o significado de determinadas respostas dos/das estudantes em certo momento? Como partir do conhecimento produzido até determinado momento para auxiliá-los/las a ir além, ampliar seus conhecimentos?

Muitas vezes, a despeito de uma precisão justa, ausente de erro ou equívoco, o/a professor/professora resume a avaliação à média de escores dos testes. Efetiva assim a concepção constatativa desse instrumento e negligencia o dinamismo próprio do trabalho pedagógico, caracterizado pela trilogia ação-reflexão-ação. E, o que é mais preocupante, não percebe que, por trás desse modelo, há uma complexa rede de interesses sociais definindo e sustentando as práticas escolares, como bem assinala Esteban (2002, p. 108):

A avaliação escolar que mantém a lógica do exame [...] é um dos métodos sociais mais suaves, corporalmente menos violentos e visualmente menos perceptíveis de manter a disciplina; [...] tem o sentido de disciplinar não só corpo, mas também (e principalmente) o pensamento, a vontade, as disposições.

Ela analisa essa concepção de avaliação como forma de disciplinamento social, adequação/enquadramento do indivíduo a valores e conhecimentos estabelecidos e reconhecidos. Tem sido esse modelo o responsável por altos índices de reprovação escolar. Torna-se urgente pensar a avaliação sob outra perspectiva, para que se garanta o pleno desenvolvimento do/da estudante no espaço escolar e, como consequência, contribua para sua inclusão na sociedade.

\section{A AVALIAÇÃO DA APRENDIZAGEM NAS DINÂMICAS INCLUSÃO/EXCLUSÃO SOCIAL E PERMANCÊNCIA/DIMINUIÇÃO DAS DESIGUALDADES SOCIAIS}

Esteban (2002) chama a atenção para a seletividade que marca a avaliação escolar que promove uns e exclui outros. Este tipo de avaliação que seleciona e classifica é arbitrário porque, muitas vezes, desconsidera que nem sempre o/a estudante compreende o que o/a professor/professora quis dizer ou não compreende da forma como esse/essa imaginou que compreenderia. Sendo assim, quando se pretende analisar a reprovação escolar, um aspecto relevante a ser considerado é a atuação docente no 
processo de avaliação, pois é a interpretação do/da professor/professora frente ao que o/a estudante apresenta que determinará o desenrolar do trabalho pedagógico. Segundo ela,

a avaliação tem estreita relação com a interpretação que o/a professor/a faz das respostas dadas, especialmente significativas no caso das crianças que chegam à escola portando estruturas de compreensão diferentes daquelas aceitas pela norma estabelecida (ESTEBAN, 2002, p. 99).

Assim, segundo a autora, em um contexto marcado por diferenças culturais, tal como observado no espaço escolar, as interações pessoais encontrar-se-ão marcadas pela pluralidade de significados. E, como consequência, diferentes grupos e sujeitos podem utilizar de diferentes modos, instrumentos e elementos similares. Compreender esse fato é fundamental, por parte do/da professor/professora, para que perceba a avaliação como ação extremamente complexa e para explicitar a produção social da reprovação escolar, pois uma proposta pedagógica que a desconsidera - por estar pautada em um discurso unívoco - não valorizará os diferentes significados da pluralidade de vozes existentes. Antes, trabalhará em uma perspectiva de treinamento. O conhecimento será substituído pela aprendizagem de estratégias que facilitem a memorização de conteúdos (ESTEBAN, 2002).

Um exemplo de tal fato ocorre quando o/a professor/professora acredita que os enunciados das questões e $o$ trabalho pedagógico que realiza terão, para diferentes estudantes, o mesmo significado que ele/ela imaginou ou que o significado será o mesmo para todos/todas. No primeiro caso, ele/ela deparar-se-á, muitas vezes, com uma resposta às questões propostas que será diferente daquela esperada. No segundo caso, irá se deparar com tantas respostas quantos forem seus/suas estudantes. Assim, podemos afirmar que a concepção de homogeneidade em que se tem fundamentado o trabalho pedagógico - e, como parte importante dele, a avaliação - é fator preponderante para a dinâmica de exclusão de estudantes da vida escolar. Por essa concepção, o/a professor/professora reduz o processo de avaliação à verificação de erros e acertos, numa atitude em consonância com uma visão tecnicista e mecânica da prática pedagógica. Quando, ao contrário, o trabalho pedagógico se pauta na concepção de heterogeneidade e pluralidade, o interesse do/da professor/professora volta-se para o reconhecimento dos conhecimentos que o/a estudante possui e de como chegou a tais conhecimentos (ou seja, que processo de aprendizagem se desenvolveu).

Quando se pretende educar para a autonomia e valorizar a multiplicidade de vozes, torna-se necessário buscar uma avaliação que contemple esses aspectos e que acredite que, para cada indivíduo, o processo será singular. É necessário que se tenha diretrizes educacionais em que haja a preocupação em garantir que o/a estudante se desenvolva a partir de um projeto educativo. Não se pode negligenciar os aspectos singulares da relação do indivíduo com o conhecimento. Nesse sentido, o/a professor/professora deveria - ao analisar o resultado de toda e qualquer tarefa realizada pelo/pela estudante - ter a preocupação de investigar suas interpretações, seus avanços, tendo em vista auxiliá-lo/la em seu processo de desenvolvimento. 
Realizada em uma perspectiva distante da investigação, a avaliação tem-se distanciado da dinâmica própria do processo de conhecimento e - o que é pior - "[...] vem dificultando a explicitação, na sala de aula, da polissemia, da polifonia e da diversidade de processos", conforme sinaliza Esteban (2002, p. 106). Torna-se necessário, assim, reconstruir o significado da ação avaliativa na escola enquanto processo permanente de acompanhamento do desenvolvimento do educando. Torna-se imprescindível também que, em sua prática cotidiana, o/a professor/professora tenha um olhar atento em relação a todas as atividades realizadas pelos/pelas estudantes, buscando investigar seus processos e compreendê-los para favorecer e ampliar suas possibilidades (HOFFMANN, 2005). E isso somente se torna possível com outro referencial educativo:

Tal mudança implica [...] uma transformação do sentido de aprendizagem escolar, ultrapassando o objetivo de aquisição do conhecimento valorizado como conhecimento escolar e tendo como horizonte a ampliação constante dos saberes que os sujeitos possuem, (re) criando sempre a necessidade de obter novos e mais complexos conhecimentos (ESTEBAN, 2002, p. 106).

A autora utiliza oportunamente e com frequência a expressão processo de conhecimento em contraposição a processo de aprendizagem. Pode parecer, à primeira vista, uma diferença sutil, mas está carregada de significação. Enquanto a segunda expressão traz consigo a ideia do "estático", de assimilação (como se houvesse algo pronto e acabado que devesse ser assimilado), a primeira expressão parece contemplar a ideia de singularidade e de movimento, pois o indivíduo busca conhecimento na medida e na direção de seus interesses. Ela reafirma a necessidade de o processo de avaliação estar pautado em outras bases que não sejam aquelas de verificação dos comportamentos ou das habilidades esperadas. Percebe-se, assim, que as implicações da avaliação ultrapassam o âmbito escolar e dimensionam aspectos sociais mais amplos. A ideia de que há uma única resposta possível está relacionada a uma hierarquização social que promove uns e exclui outros.

Barriga (apud GARCIA, 2003) chama a atenção para a questão da mobilização do esquema referencial de cada estudante (o conjunto de conhecimentos, sentimentos e afetos que configuram o seu ser) no processo de aprendizagem. Segundo ele, é esse esquema que media o processo, sempre que aquele se vê diante da necessidade de ampliar seus conhecimentos. As implicações dessas considerações para a reconfiguração da avaliação são importantíssimas. Em primeiro lugar, trazem a ideia de que a aprendizagem acontece por uma necessidade do indivíduo - ou seja, uma motivação particular - o que já demonstra uma autonomia sua. Em segundo lugar, mostra que o resultado do processo de aprendizagem é singular, pois os esquemas referenciais que entrarão em contato com os objetos de conhecimento serão diferentes, produzindo uma pluralidade de significações. Sendo assim, é possível perguntar: como estabelecer um padrão para avaliar? Estabelecendo-o, certamente, haverá a valorização de algum esquema de significação e a rejeição de outros.

\section{A AVALIAÇÃO ENTRE DUAS LOGICAS E A LÓGICA QUE SUPERA A IDEIA DE "FRACASSO ESCOLAR"}


São muitas as propostas que pretendem dar conta da superação da reprovação escolar e, atrelada a ela, a ideia de "fracasso escolar". Perrenoud (1999) propõe que a escola realize um ensino diferenciado e uma observação formativa como instrumentos de regulação das aprendizagens. Mostra que as proposições didáticas efetuadas de maneira uniforme pelo/pela professor/professora serão certamente inadequadas para algumas crianças. O resultado é que algumas se motivarão e se desenvolverão e outras - para quem tais proposições não terão qualquer sentido - não. Sendo assim, defende o acompanhamento individualizado, pois o percurso de cada estudante é singular. Sinaliza que é primordial elaborar e desenvolver atividades e situações de aprendizagem que sejam diversificadas segundo as diferenças pessoais e culturais. E, segundo ele, a avaliação que está em consonância com esta pedagogia das diferenças é a formativa, que pode ao permitir aos/às estudantes identificar suas dificuldades e erros - ajudá-los/las a progredir.

Já Esteban (2002) afirma que é preciso reconstruir o sentido e a ação da produção de conhecimento em sua totalidade para que haja uma redefinição da teoria e da prática da avaliação escolar. Segundo ela, a avaliação tem considerado como padrão de resposta apenas o conhecimento científico, negando/rejeitando o conhecimento advindo do senso comum. Alinha-se com Santos (1993) e seu conceito de senso comum renovado para mostrar que somente desfazendo a ideia de que o conhecimento científico é que deve ser considerado verdadeiro é que se poderá pensar uma nova teoria da avaliação. Como afirma esse autor, o senso comum e o conhecimento científico são explicações da realidade que, na relação dialógica estabelecida na escola, se confrontam e que se alternam mutuamente, produzindo novos significados e sentidos.

É preciso, assim, redimensionar o sentido da avaliação da aprendizagem, articulando-o com um compromisso verdadeiro com a democracia. Mas isso somente irá se tornar possível dentro de um processo amplo de redefinição da própria prática pedagógica. Esteban (2002) sinaliza como, condição fundamental para essa reconfiguração, o conceito de dupla ruptura epistemológica² proposto por Santos (1993). No movimento de reconstrução do processo de avaliação em articulação com esse movimento de dupla ruptura epistemológica, o conceito vygotskiano de zona de desenvolvimento proximal, segundo a autora, é primordial, pois representa o lugar mesmo das possibilidades: o que normalmente seria encarado como erro passa a ser visto como um estágio para o vir a ser. Apesar de senso comum e conhecimento científico se renovarem mutuamente a partir da relação dialógica estabelecida é preciso enfatizar que a nova estrutura, em ambas as partes, não será cópia uma da outra, pois que estará, conforme sinaliza a autora, marcada por uma reconstrução individual do conhecimento, para a qual colaborará o ponto de partida de cada estudante. Nessa perspectiva, muda o enfoque/compreensão sobre a noção de erro. Ele passa a ser visto como uma possibilidade de compreensão, resultado da leitura que o/a estudante fez do conhecimento com o qual interagiu.

Sendo assim, o/a professor/professora precisa apropriar-se da interpretação do/da estudante, pois uma resposta diferente da esperada por ele/ela não significa erro ou ausência de conhecimento, como tradicionalmente tem sido compreendida nessa noção 
na escola. É uma elaboração própria de conhecimento daquele/daquela, a partir das ferramentas e conhecimentos que possui. Torna-se necessário, assim, segundo a autora, atenção para o fato que professores e estudantes têm interpretações distintas das palavras uns dos outros. E essa relação se torna mais comprometedora na direção do/da professor/professora para o/a estudante, pois aquele/aquela não poderá ajudar esse/essa em seu processo de desenvolvimento se não conseguir identificar a lógica subjacente à sua resposta, tendo em vista a dinamização da continuidade do processo.

Há hoje no Brasil um discurso da necessidade de que a avaliação funcione como um mecanismo de garantia de qualidade. Consequentemente, o que se tem observado nesse campo é uma ideia de avaliação associada à ideia de controle e valorização das excelências, resultando no menosprezo pelas diferenças que não atendam ao padrão estipulado em um processo que inclui uns e exclui outros, promovendo nesses últimos, muitas vezes, o desenvolvimento de uma autoimagem negativa. É imprescindível que professores e professoras tenham consciência disso e percebam que precisam se posicionar criticamente frente aos modelos existentes. Não há como não perceber o caráter político envolvido no ato avaliativo, como parte significativa da prática pedagógica. Conforme Garcia (2003), compreendendo diferentes lógicas, ele pode, com efeito, valorizar a lógica hegemônica que respalda o processo de discriminação e exclusão que sempre penalizou os/as filhos/filhas de trabalhadores e trabalhadoras, os/as afrodescendentes e indígenas.

Um olhar ou postura ingênua do/da docente em relação à avaliação faz com que ela seja a responsável pela manutenção da estratificação social presente em nossa sociedade, pois Ihe dá uma "aparência de consequência natural das diferenças individuais que caracterizam os seres humanos" (ESTEBAN, 2002, p. 107). Nessa lógica, alguns/algumas se esforçam e conseguem atingir o padrão; outros/outras não. Garcia (2003) afirma que quem estabelece as normas já prevê antecipadamente os vencedores. Assim como Esteban (2002), a autora também concorda com Barriga (1982) de que é necessário que haja uma ruptura epistemológica, configurando outra forma de tratar o conhecimento para que haja a democratização das práticas pedagógicas. A avaliação, nessa nova perspectiva, precisa ser negociada: as partes envolvidas precisam dialogar e definir juntas o que será valorizado no processo pedagógico e, além disto, o/a professor/professora precisa garantir a todos e a todas a continuidade do processo de desenvolvimento.

\section{CONSIDERAÇÕES FINAIS}

Tendo em vista a peculiaridade da relação que cada indivíduo estabelece com o objeto de conhecimento, ressignificando-o a partir de suas experiências e vivências pessoais, é imprescindível que se crie na escola uma proposta de avaliação que esteja em consonância com essa perspectiva. É preciso haver a compreensão, por parte de professores e professoras, que - diante de uma proposta educativa - surgirão diferentes posicionamentos e interações. Há dois paradigmas orientando as práticas escolares e esses conformam modelos de avaliação bem distintos: um que regula e outro que promove e emancipa. A prática pedagógica não é e nem pode ser neutra. O/a professor/professora precisa ter clareza em relação a que tipo de indivíduo pretende 
formar, que sociedade ele quer ajudar a construir. Se ele/ela pretende educar para a autonomia e ajudar a romper com os laços de dominação que têm sustentado uma sociedade injusta, desigual, precisa estar atento/atenta à forma própria como o/a estudante lida com o conhecimento, que significado está dando para as propostas educacionais às quais é submetido/submetida.

Para cada estudante o resultado das interações será singular. É por isso que a perspectiva de avaliação que considera o significado elaborado pelo/pela estudante e procura romper com o paradigma objetivista mostra-se a mais adequada a mudanças e à ruptura com padrões pré-estabelecidos. Assim, há a necessidade de estabelecimento de um espaço dialógico em sala de aula, além de criação de atividades que permitam conhecer os diferentes significados. Percebe-se que o processo amplo e complexo da prática de avaliação encontra-se, muitas vezes, reduzido às suas ferramentas. $O$ que, na escola, convencionou-se chamar de "testes" ou "provas" tem sido encarado como instrumentos sentensivos e precisos para mostrar a qualidade do trabalho pedagógico. $\mathrm{O}$ uso dos "testes" como instrumentos sentensivos tem se constituído um entrave para a prática pedagógica e para uma avaliação que se oriente pela perspectiva da inclusão.

Ao estabelecer um padrão de resposta e verificar se os/as estudantes correspondem a ele ou não, a escola nada mais faz do que atender a um sistema educativo organizado por princípios homogeneizadores e excludentes, que contribui para a manutenção das desigualdades. Desconsidera, assim, as diferenças e o entendimento de que o/a estudante ressignifica o objeto de conhecimento a partir de suas vivências. Nessa perspectiva, não há a valorização de conhecimentos resultantes de lógicas diferentes da lógica estabelecida como padrão. O que verdadeiramente importa quando se trata da avaliação é o uso que se faz dos resultados apresentados pelos/pelas estudantes nas observações realizadas (seja por quais métodos ou instrumentos que o/a professor/professora utilizar). Antes de se perguntar: "Como avaliar?" deve-se perguntar: "Para que avaliar?". Ou seja, é preciso que professores/professoras estejam atentos/atentas em primeiro lugar às funções da avaliação, pois ela tem servido muito mais a mecanismos de reprovação do que à promoção. Se o que se pretende é construir uma escola democrática, torna-se necessário considerar o significado particular que cada estudante dá aos conhecimentos que elabora a partir da prática pedagógica que vivencia. Não se pode querer impor nenhum ponto de vista, enraizá-lo. Quando se tem esse entendimento, assume-se um compromisso com o/a estudante, o que se traduz em uma busca permanente por igualdade social e uma tentativa contínua de garantir que ele/ela avance a partir do ponto em que se encontra. 


\section{SCHOOL EVALUATION - A PRACTICE BETWEEN TWO LOGIC: WHAT EMANCIPATES AND REPROVES SOCIAL INEQUALITIES}

RESUMEN: This work seeks, through a bibliographical analysis, to propose reflections on school evaluation. It shows that this practice in the Basic Education school has been one of the central issues of teaching work. It analyzes the different functions of assessment and discusses the representations of teachers, identifying the misconceptions that surround it. It points to the need to break with educational paradigms that conceive it as a reproductive mechanism of inequalities and stresses the need for an action that allows to embrace the multiplicity of situations and processes of development of students as an important measure in the field of education. to break social inequalities.

PALABRAS CLAVE: Evaluation. Social inclusion. Epistemological rupture. Basic education.

\section{EVALUACIÓN DE LA ESCUELA - UNA PRÁCTICA ENTRE DOS LÓGICAS: QUÉ EMANCIPA Y REPONE LAS DESIGUALDADES SOCIALES}

RESUMEN: Este trabajo busca, mediante un análisis bibliográfico, proponer reflexiones sobre la evaluación escolar. Muestra que esta práctica, en la escuela de Educación Básica, se ha constituido en una de las cuestiones centrales del trabajo docente. Analiza las diferentes funciones de evaluación y discute las representaciones de los docentes, identificando los conceptos erróneos que lo rodean. Señala la necesidad de romper con los paradigmas educativos que lo conciben como un mecanismo reproductivo de las desigualdades y subraya la necesidad de una acción que permita abarcar la multiplicidad de situaciones y procesos de desarrollo de los estudiantes como una medida importante en el campo de la educación. para romper las desigualdades sociales.

PALABRAS CLAVE: Evaluación. Inclusión social. Ruptura epistemológica. Educación básica.

\section{NOTAS}

1) Este conceito refere-se à concepção de senso comum enriquecido com as contribuições do conhecimento científico, que também é por ele enriquecido, em um movimento dialógico.

2) O termo representa a segunda mudança paradigmática que é proposta. A primeira foi proposta por Bachelard (1974) e preconizava a superação do senso comum pelo conhecimento científico. Nessa segunda ruptura, propõe-se uma ruptura com a ruptura bachelardiana: tanto o senso comum quanto a ciência se transformam. 


\section{REFERÊNCIAS}

BACHELARD, G. La formación del espíritu científico. Buenos Aires: Siglo XXI, 1974.

BARRIGA, A. D. Tesis para la elaboración de uma teoria de la evaluación y sus derivaciones em la docência: perfiles educativos. México: Centro de Investigaciones y Servicios Educativos de la UNAM, 1982.

BOURDIEU, P. \& PASSERON, J. C. A reprodução: elementos para uma teoria dos sistemas de ensino. Rio de Janeiro: Francisco Alves, 1975.

ESTEBAN, M. T. O que sabe quem erra? Reflexões sobre avaliação e fracasso escolar. 3. ed. Rio de Janeiro: DP\&A Editora, 2002.

FRANCO, M. L. P. B. Pressupostos epistemológicos da avaliação educacional. In: SOUZA, C. de P. Avaliação do rendimento escolar. São Paulo: Papirus, 1995.

GARCIA, R. L. A avaliação e suas implicações no fracasso/ sucesso. In: ESTEBAN, M. T. Avaliação: uma prática em busca de novos sentidos. 5. ed. Rio de Janeiro: DP\&A, 2003.

HOFFMANN, J. Avaliação: mito e desafio; uma perspectiva construtivista. 35. ed. Porto Alegre: Mediação, 2005.

PERRENOUD, Ph. Avaliação: da excelência à regulação das aprendizagens; entre duas lógicas. Porto Alegre: Artmed, 1999.

SANTOS, B. S. Introdução a uma ciência pós-moderna. Porto: Afrontamento, 1993.

STUFFLEBEAN, D. Evaluación sistemática: Guía teórica y práctica. Barcelona: Paidós, 1987.

\footnotetext{
Vera Regina Souza dos Santos: Doutoranda em Educação pela Universidade Federal do Estado do Rio de Janeiro, na linha de pesquisa Políticas e práticas em Educação. Mestre em Educação pela Universidade Federal do Estado do Rio de Janeiro.

ORCID: https://orcid.org/0000-0001-9853-5748

E-mail:verarssantos@yahoo.com.br
}

Este periódico utiliza a licença Creative Commons Attribution 3.0, para periódicos de acesso aberto (Open Archives Iniciative - OAI). 